\title{
Resistência de grãos de milho à ruptura por compressão
}

\author{
Corn grain resistance to rupture by compression
Hevandro Colonhese Delalibera' ${ }^{\mathrm{I}}$ Pedro Henrique Weirich Neto ${ }^{\mathrm{I}^{*}}$ Marcelo José Colet $^{\mathrm{II}}$ Paulo William Garbuio ${ }^{\mathrm{I}}$ Claudio Bianor Sverzut ${ }^{\mathrm{II}}$

\section{RESUMO}

A região dos Campos Gerais é considerada um importante pólo leiteiro do Paraná. No que se refere à alimentação de gado leiteiro, destaca-se a silagem de planta inteira de milho, em que a otimização no aproveitamento desta é fator importante, pois reduz os custos da produção. Com vistas a tal otimização, um dos fatores que merece destaque é a digestibilidade dos grãos, a qual é influenciada pelo híbrido, pelas condições da cultura, pelo ponto de colheita e pelo processo físico de fragmentação. Com isso, torna-se importante conhecer as propriedades mecânicas dos materiais vegetais e quantificar as exigências de força necessárias para fragmentá-los, pois são parâmetros relevantes no desenvolvimento de máquinas que desempenham esta função. Neste trabalho quantificou-se a exigência de força para romper grãos de milho por compressão para 11 híbridos comumente utilizados na região. Na avaliação foram utilizados grãos colhidos no ponto de grão seco. Para tanto, utilizou-se uma célula de carga, um sistema hidráulico com velocidade constante e uma ponteira em forma de "V". Na quantificação da força, foram encontradas exigências distintas entre os híbridos, mesmo quando estes possuem a mesma classificação quanto à textura do grão (mole e/ou semiduro). A exigência de força foi diretamente proporcional à quantidade de endosperma córneo.

Palavras-chave: silagem, textura do grão, propriedades mecânicas de grãos.

\section{ABSTRACT}

The region of Campos Gerais, in the State of Paraná, is considered a distinct dairy farming center. Wholeplant corn silage is a very common regional practice as complementary feeding strategy for dairy cows and the optimization of its use is considered essential in order to reduce production costs. Grain digestibility plays a major role in this process and it is influenced by the hybrid, field conditions, point of harvest and grinding level. The identification of mechanical properties of plant materials, and the quantification of the force required to fragment those materials are relevant parameters for the design of new machinery, able to fulfill such demand. The aim of this study was to quantify the amount of force necessary to fragment corn grains by compression for eleven hybrids commonly planted in the region. For the evaluation purpose, grains harvested at dry stage were employed. Testing equipment consisted of a load cell, a hydraulic system with constant speed, and a V-shaped tip. Results showed that the force of rupture was different for each hybrid, even for those in the same grain texture class ("dent" and/or "flint"). The amount of force necessary was directly proportional to the quantity of corneous endosperm in the grain.

Key words: silage, grain texture, mechanical properties of grains.

\section{INTRODUÇÃO}

A região dos Campos Gerais é considerada um importante pólo leiteiro do Paraná, onde a microrregião de Ponta Grossa (Carambeí, Castro, Palmeira e Arapoti) é responsável por 53,5\% da produção da região Sul, sendo que tal região produz 28,6\% do leite do Estado (RONSANI \& PARRÉ, 2003). O município de Castro, seguido por Carambeí, possui um dos melhores rebanhos do país, isso graças ao alto potencial genético dos animais, os quais são altamente especializados para esta finalidade.

Porém, para que os animais alcancem os índices de produtividade preconizados, necessitam de níveis adequados de energia, que normalmente são

ILaboratório de Mecanização Agrícola (Lama), Universidade Estadual de Ponta Grossa (UEPG). Av. General Carlos Cavalcanti, n. 4748, 84030-900, Ponta Grossa, PR, Brasil. E-mail: lama1@uepg.br. *Autor para correspondência.

"Faculdade de Engenharia Agrícola (FEAGRI), Universidade Estadual de Campinas (Unicamp), Campinas, SP, Brasil. 
alcançados com concentrados e volumosos. No caso dos volumosos, é comum a utilização de silagem de planta inteira de milho, devido à grande quantidade de grãos, o qual torna a silagem altamente energética. Quando se utiliza este tipo de fonte, o processamento físico é de extrema importância, pois a natureza física do material pode ser alterada, reduzindo a habilidade deste em estimular a ruminação, o fluxo de saliva e a disponibilidade do material ao processo digestivo, diminuindo o aproveitamento do alimento e, conseqüentemente, os rendimentos (RIPPEL et al., 1998).

Tais problemas normalmente são observados no aproveitamento dos grãos de milho, pois estes são cobertos e protegidos pelo pericarpo, o qual é muito resistente à degradação microbiana e à digestão enzimática no intestino delgado do animal, sendo necessário, então, que os mesmos sofram um processo de fragmentação adequado (JOBIM et al. 2003).

Para alcançar os tamanhos adequados dos fragmentos no processo de ensilagem, fatores classificados como extrínsecos e intrínsecos à máquina merecem atenção. As características intrínsecas se referem às dimensões construtivas do dispositivo de corte e/ou regulagens e os fatores extrínsecos são aqueles relacionados às condições de operação, como quantidade de massa e taxa de alimentação, e aqueles relacionados com o material a ser cortado (PRASAD \& GUPTA, 1975). Os fatores intrínsecos também podem ser somados aos extrínsecos na exigência de força para fragmentar ou romper o material vegetal (BIANCHINI \& MAGALHÃES, 2004).

Com relação à resistência, os materiais vegetais possuem propriedades que são conhecidas como viscoelasticidade. Esta é caracterizada pela constituição do material, na qual a parede celular qualifica a propriedade elástica e os fluidos quantificam a propriedade viscosa, onde a variação destes e a localização da água promovem escalas distintas de resistência. Assim, o material vegetal morto e úmido tende a oferecer maior resistência ao corte devido ao incremento da viscoelasticidade e, com o decréscimo do conteúdo de água, diminui-se a viscoelasticidade, tornando-se mais fácil de cortar. Para o material vivo, ocorre o inverso, pois, ao invés de a água estar entre e/ ou absorvida pelas fibras, esta encontra-se dentro das células, que, quando sofrem a ação de uma solicitação externa, logo extravasam o conteúdo celular, oferecendo menor resistência para a ruptura (PRASAD \& GUPTA, 1975; CHOI \& ERBACH, 1986).

Visto que tanto a fragmentação de grãos quanto a fragmentação de outros materiais de origem vegetal é de grande importância para a agricultura e a pecuária, torna-se necessário estudar a resistência de materiais de origem vegetal, pois estes são parâmetros relevantes no desenvolvimento de máquinas que desempenham esta finalidade (BIANCHINI \& MAGALHÃES, 2004).

\section{MATERIAL E MÉTODOS}

O trabalho foi desenvolvido no Laboratório de Mecanização Agrícola (Lama) da Universidade Estadual de Ponta Grossa (UEPG), em conjunto com a Faculdade de Engenharia Agrícola (Feagri) da Universidade Estadual de Campinas (UNICAMP). Para a quantificação da resistência à ruptura dos grãos de milho, utilizou-se uma célula de carga do tipo "S", modelo Z-500, com carga máxima para 5000N, calibrada no Centro de Tecnologia (CT - UNICAMP) e um sistema de aquisição eletrônica de dados em interface com um microcomputador portátil, gerenciado pelo programa computacional Catman v. 1.2.

Utilizou-se na determinação desta variável uma ponteira em forma de "V", com um ângulo de ataque de $45^{\circ}$ e dimensões de: $43,5 \mathrm{~mm}$ de altura, 25,75mm de largura e 36,20 mm de comprimento, sendo a espessura da área de contato com o grão (vértice da ponteira) de $2 \mathrm{~mm}$. A taxa de aquisição de dados foi de $1200 \mathrm{~Hz}$ e a velocidade de aplicação da força de 30,48mm s ${ }^{-1}$, obtendo-se 39,4 valores de resistência à compressão por milímetro de deslocamento da ponteira.

Como tratamentos, foram utilizados 11 híbridos de milho cultivados na região, caracterizados conforme a tabela 1 . A semeadura foi realizada no dia 2 de novembro de 2005, utilizando-se uma semeadoraadubadora de precisão composta de nove linhas e espaçadas $0,6 \mathrm{~m}$, com mecanismos dosadores regulados

Tabela 1 - Características agronômicas dos híbridos utilizados.

\begin{tabular}{lll}
\hline Híbrido & \multicolumn{1}{c}{ Aptidão } & Textura do grão \\
\hline H-1 & grão & semiduro \\
H-2 & grão & semiduro \\
H-3 & grão/SPI ${ }^{1}$ SGU & semiduro \\
H-4 & grão/SPI & mole \\
H-5 & grão & semiduro \\
H-6 & grão/SGU & mole \\
H-7 & grão & semiduro \\
H-8 & grão/SPI & semiduro \\
H-9 & grão & semiduro \\
H-10 & grão & semiduro \\
H-11 & grão/SPI & semiduro \\
\hline
\end{tabular}

1 - Silagem de planta inteira; 2- Silagem de grão úmido. Fonte: EMBRAPA (2004).

Ciência Rural, v.38, n.9, dez, 2008. 
para depositar quatro sementes $\mathrm{m}^{-1}$, onde foram semeadas 27 linhas de 200m para cada híbrido. Utilizouse como adubação de base $300 \mathrm{~kg} \mathrm{ha}^{-1}$ da fórmula 1434-00 (N-P-K) e como cobertura $275 \mathrm{~kg} \mathrm{ha}^{-1}$ da formulação 36-00-12 (N-P-K) incorporada ao solo. Também foram realizadas duas aplicações de adubação foliar nas dosagens 1 e 2,5L ha-1.

Para avaliação de resistência à compressão, foram utilizados 55 grãos (repetições) escolhidos ao acaso em uma amostra de cinco espigas para cada um dos 11 tratamentos, as quais foram retiradas do campo no ponto de colheita de milho seco. Determinou-se a resistência da parte superior do grão, pois dessa forma eram esperadas maiores diferenças na resistência entre os híbridos, devido às variações da quantidade de endospermas córneo e amiláceo, pois, segundo BRASIL (1976), estes tem influência direta na resistência dos grãos, embora a classificação utilizada dê maior ênfase para o formato da coroa do grão. Com base nos valores de força de ruptura $(\mathrm{N})$ e nas dimensões dos grãos, foi calculada a força específica (MPa).

Das mesmas amostras de cinco espigas de cada um dos 11 tratamentos, ainda foram coletados 25 grãos (repetições), também ao acaso, para mensuração das características biométricas, bem como foram retiradas quatro amostras de $30 \mathrm{~g}$ para determinação do conteúdo de água. Este último foi determinado em estufa de ar forçado a $60^{\circ} \mathrm{C}$, até estabilização da massa.

Outra amostra de 25 grãos foi utilizada para estimar as massas relativas dos componentes do grão, separando-os em três partes: endosperma córneo, endosperma amiláceo e pericarpo mais embrião. Por meio de processo visual e manual, estimaram-se os componentes dos grãos nos respectivos híbridos, utilizando um instrumento de corte para tanto. Para esta mensuração, não foi realizada análise estatística pelo fato de não haver repetições, isto é, os 25 grãos compunham uma única amostra.

Para cada caso citado anteriormente, foi realizada análise de variância com posterior teste de médias (Tukey em nível de 5\% de probabilidade de erro), utilizando delineamento experimental inteiramente casualizado. Realizou-se também análise de regressão entre a variável de resposta força exigida para a ruptura dos grãos e a massa relativa de endospermas córneo e amiláceo, com o intuito de descobrir se existe relação entre estes.

\section{RESULTADOS E DISCUSSÃO}

De acordo com as características dimensionais, conforme tabela 2, os tratamentos H-8 e $\mathrm{H}-10$ apresentaram os maiores valores para a largura e para a espessura do grão.
Tabela 2 - Valores médios e respectivos coeficientes de variação (CV) da largura e espessura dos grãos.

\begin{tabular}{lcccc}
\hline & & \multicolumn{2}{c}{------Largura------ } & \multicolumn{2}{c}{-----Espessura----- } \\
Híbrido & & & & \\
& Média (mm)* & CV \% & Média $(m m)^{*}$ & CV \% \\
\hline H-1 & 9,20 b & 7,14 & 4,45 c & 6,60 \\
H-2 & 9,16 b & 6,35 & 4,32 bc & 7,00 \\
H-3 & 8,86 ab & 5,28 & 4,25 b & 5,52 \\
H-4 & 9,45 bc & 5,42 & 4,40 bc & 8,85 \\
H-5 & 8,76 ab & 4,85 & 4,11 ab & 6,55 \\
H-6 & 9,41 bc & 6,54 & 4,49 c & 7,56 \\
H-7 & 8,62 a & 5,93 & 4,55 cd & 6,38 \\
H-8 & 9,26 bc & 8,55 & $4,60 \mathrm{~cd}$ & 6,75 \\
H-9 & 9,70 c & 5,07 & 4,04 a & 4,62 \\
H-10 & 9,40 bc & 4,82 & 4,57 cd & 5,87 \\
H-11 & 8,47 a & 6,08 & 4,77 d & 5,33 \\
\hline
\end{tabular}

*Médias de tratamentos não seguidas por mesma letra, na coluna, diferem entre si pelo teste de Tukey em nível de 5\% de probabilidade de erro.

Para as quantidades dos endospermas demonstrados na tabela 3 , excluindo os tratamentos H-6 e H-4 (Tabela 1), todos os outros seriam comercialmente classificados como semiduros (EMBRAPA, 2004). Porém, observou-se que existe grande variação entre os híbridos, mesmo quando estes apresentam a mesma classificação da textura do grão. Pode-se observar que o tratamento $\mathrm{H}-4$, classificado como grão de textura mole, apresenta maior quantidade de endosperma córneo que o híbrido $\mathrm{H}-5$, que possui classificação como textura do grão semiduro (Tabela 1). Nas variáveis de composição dos grãos (embrião e endospermas córneo e amiláceo), não foi realizada análise de variância, pois a quantificação destas é trabalhosa, inviabilizando muitas amostras.

Para o conteúdo de água, a análise de médias mostrou que existem diferenças entre os tratamentos (Tabela 3), que, segundo PRASAD \& GUPTA (1975) e CHOI \& ERBACH (1986), é um fator determinante para a comparação da força de resistência do material vegetal. Sendo assim, os tratamentos são separados em grupos, significativamente, com os mesmos conteúdos de água. Nesta classificação chegou-se a quatro grupos, como mostra a tabela 4 . O tratamento H-6 não se enquadrou em nenhum grupo.

No grupo denominado de $16 \%$ (conteúdo de água dos grãos em torno de $160 \mathrm{~g} \mathrm{~kg}^{-1}$ ), houve diferença da força específica, pois o tratamento $\mathrm{H}-11$ possui menor largura e, conseqüentemente, menor área de contato entre ferramenta e grão, para uma mesma exigência de força $(\mathrm{N})$.

No grupo $17 \%$ e no grupo $18 \%$, o tratamento H-9 apresentou a maior exigência de força para ruptura, 
Tabela 3 - Constituição em massa relativa, comparação de médias e respectivo coeficiente de variação (CV) do conteúdo de água dos grãos.

\begin{tabular}{|c|c|c|c|c|c|}
\hline Híbrido & Embrião (g kg-1) & End. córneo ( $\mathrm{g} \mathrm{kg}^{-1}$ ) & End. amiláceo ( $\left.\mathrm{g} \mathrm{kg}^{-1}\right)$ & Conteúdo de água $\left(\mathrm{g} \mathrm{kg}^{-1}\right)^{*}$ & CV - Cont. água (\%) \\
\hline $\mathrm{H}-1$ & 148,9 & 656,9 & 194,2 & 169,5 bc & 0,54 \\
\hline $\mathrm{H}-2$ & 137,0 & 677,1 & 186,0 & 200,7 e & 3,21 \\
\hline $\mathrm{H}-3$ & 139,6 & 542,0 & 318,4 & $172,3 \mathrm{~cd}$ & 0,56 \\
\hline $\mathrm{H}-4$ & 147,3 & 595,3 & 257,5 & 204,3 e & 2,91 \\
\hline H-5 & 137,6 & 525,2 & 337,2 & $180,0 \mathrm{~cd}$ & 0,01 \\
\hline H-6 & 126,5 & 405,9 & 467,6 & 144,4 a & 2,52 \\
\hline H-7 & 137,4 & 666,3 & 196,3 & $186,8 \mathrm{~d}$ & 3,13 \\
\hline H-8 & 157,0 & 663,2 & 179,8 & 201,7 e & 3,27 \\
\hline H-9 & 126,3 & 707,7 & 166,0 & $179,3 \mathrm{~cd}$ & 1,47 \\
\hline $\mathrm{H}-10$ & 133,5 & 680,5 & 186,0 & $185,0 \mathrm{~d}$ & 0,44 \\
\hline $\mathrm{H}-11$ & 128,4 & 669,9 & 201,7 & 158,5 b & 0,57 \\
\hline
\end{tabular}

* Médias de tratamentos não seguidas por mesma letra, na coluna, diferem entre si pelo teste de Tukey em nível de 5\% de probabilidade de erro.

o que pode ser atribuído à quantidade de endosperma córneo. No grupo 20\%, embora o tratamento H-8 apresentasse a maior largura e espessura e, quantidade de endosperma córneo semelhante ao tratamento $\mathrm{H}-2$, o último ainda apresentou-se estatisticamente superior quanto às exigências para ruptura do grão. Tal fato pode ser explicado pela distribuição dos endospermas dentro do grão, diferença observada durante a

Tabela 4 - Análise de médias e coeficiente de variação (CV) da exigência de forças para ruptura do grão, de acordo com os grupos de umidade.

\begin{tabular}{|c|c|c|c|c|c|}
\hline Grupo & Híbrido & Força $(\mathrm{N})$ & $\begin{array}{r}\text { Força e } \\
(\mathrm{M}\end{array}$ & $\begin{array}{l}\text { specífica } \\
\text { Pa) }\end{array}$ & CV\% \\
\hline \multirow{2}{*}{$16 \%$} & H-1 & $415.31 \mathrm{a}$ & 22.58 & $\mathrm{a}$ & 32,73 \\
\hline & $\mathrm{H}-11$ & 480.33 a & 28.12 & $\mathrm{~b}$ & 27,89 \\
\hline \multirow{4}{*}{$17 \%$} & $\mathrm{H}-1$ & $415.31 \mathrm{~b}$ & 22.58 & $\mathrm{~b}$ & 32,73 \\
\hline & $\mathrm{H}-3$ & 354.71 a & 20.23 & $a b$ & 24,33 \\
\hline & H-5 & $335.00 \mathrm{a}$ & 19.12 & a & 30,81 \\
\hline & H-9 & 548.09 с & 28.26 & c & 19,63 \\
\hline \multirow{5}{*}{$18 \%$} & $\mathrm{H}-3$ & $354.71 \mathrm{ab}$ & 20.23 & $a b$ & 24,33 \\
\hline & $\mathrm{H}-5$ & $335.00 \mathrm{a}$ & 19.12 & $\mathrm{a}$ & 30,81 \\
\hline & $\mathrm{H}-10$ & $368.93 \mathrm{ab}$ & 19.62 & $\mathrm{a}$ & 23,37 \\
\hline & $\mathrm{H}-7$ & $377.07 \mathrm{~b}$ & 22.31 & $\mathrm{a}$ & 26,40 \\
\hline & H-9 & 548.09 с & 28.26 & c & 19,63 \\
\hline \multirow{3}{*}{$20 \%$} & $\mathrm{H}-2$ & $461.21 \mathrm{c}$ & 25.18 & c & 24,63 \\
\hline & $\mathrm{H}-4$ & 296.85 a & 15.71 & $\mathrm{a}$ & 32,88 \\
\hline & H-8 & $399.23 \mathrm{~b}$ & 21.93 & $\mathrm{~b}$ & 26,59 \\
\hline - & H-6 & 296.75 - & 17.04 & - & 31,19 \\
\hline
\end{tabular}

Médias de tratamentos não seguidas por mesma letra, na coluna, diferem entre si pelo teste de Tukey em nível de $5 \%$ de probabilidade de erro. quantificação dos componentes do grão. Os endospermas podem concentrar-se próximos da coroa, no centro ou na base do grão, dependendo do híbrido.

Mesmo não explicando por completo o fenômeno resistência dos grãos à ruptura por compressão, a quantidade de endosperma córneo presente nos grãos influencia as propriedades mecânicas destes. A figura 1 mostra a relação entre a quantidade dos endospermas, córneo e amiláceo, e a força necessária para ruptura do grão. Embora o coeficiente de determinação não seja elevado, estes ainda são considerados bons, segundo CHOI \& ERBACH (1986) e SHINNERS et al. (1988), por se tratar de material vegetal.

É possível observar na figura 1 as relações entre a quantidade dos endospermas e a exigência de força, mesmo havendo conteúdo de água diferente entre os tratamentos. Embora este não tenha sido quantificado separadamente, acredita-se que o conteúdo de água do grão não tenha afetado de forma significativa, pois as diferenças no conteúdo de água dos endospermas são menores que as expressas para os grãos porque a maior parte de tal conteúdo tende a se concentrar no embrião. Considerando que a força foi aplicada na parte superior do grão e que o embrião encontra-se na parte inferior do mesmo, pode-se concluir que, teoricamente, parte da diferença de conteúdo de água presente no grão foi excluída do processo de quantificação da força para ruptura.

Quanto às outras características biométricas (largura e espessura), não foi encontrada correlação com a força para ruptura por compressão dos grãos.

\section{CONCLUSÕES}

Existem exigências de força distintas para a fragmentação de grãos por compressão entre híbridos

Ciência Rural, v.38, n.9, dez, 2008. 


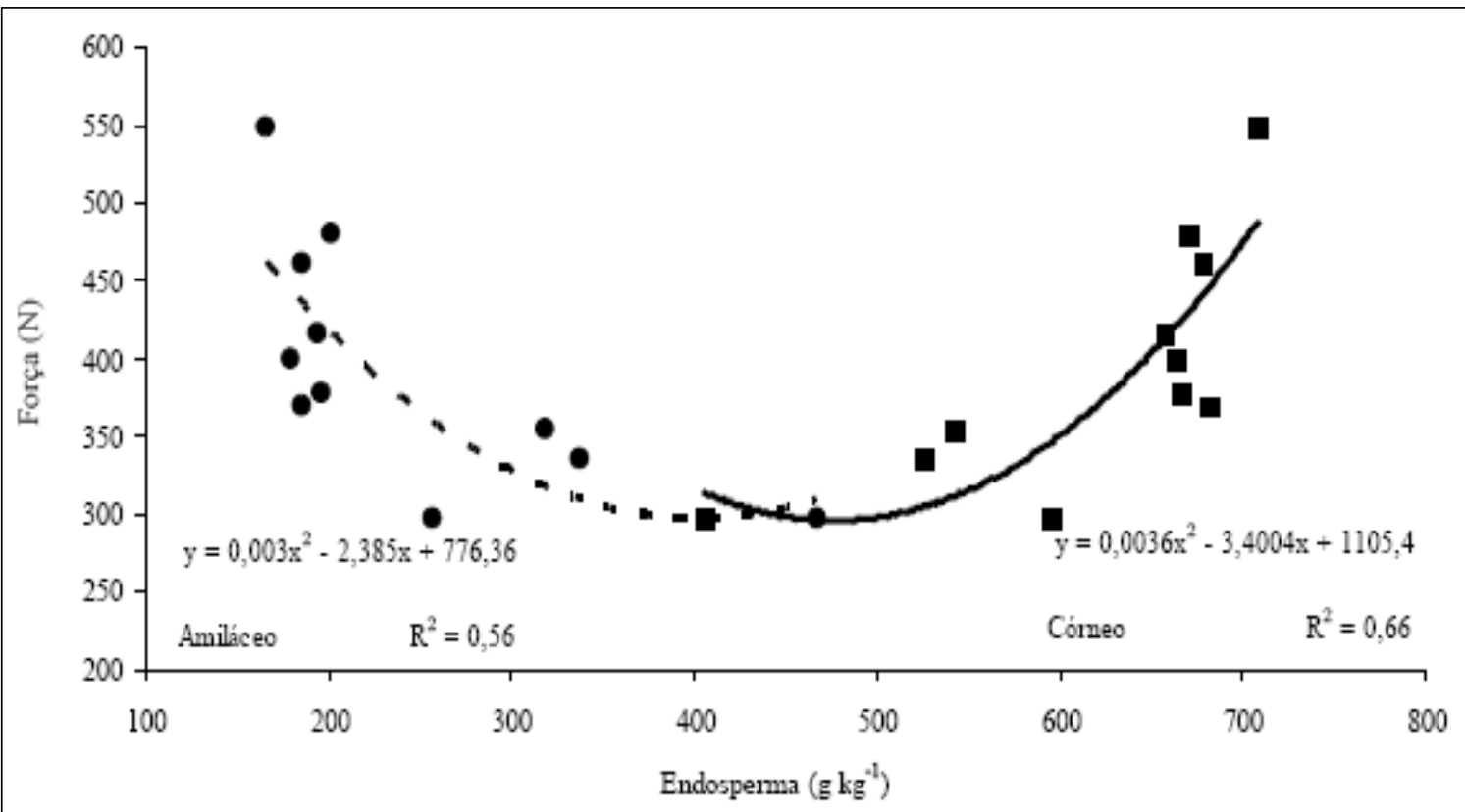

Figura 1 - Força exigida para ruptura dos grãos conforme massa relativa de endospermas amiláceo e córneo.

com a mesma classificação textural do grão (mole e/ou semiduro), sendo esta exigência proporcional à quantidade de endosperma córneo.

\section{REFERÊNCIAS}

BIANCHINI, A.; MAGALHÃES, P.S.G. Comportamento da palha de cana de açúcar submetida ao corte por meio de ensaios de bancada. Revista Brasileira de Engenharia Agrícola e Ambiental, Campina Grande, v.8, n.2/3, p.304-310, 2004.

BRASIL. Ministério da Agricultura. Especificações para a padronização, classificação e comercialização interna do milho (Zea mays L.). Portaria no 845 de 08 de novembro de 1976. Acesso em: 15/02/2006. On line. Disponível em: http:/ /www.engetecno.com.br/legislacao/ cereais_milho.htm.

CHOI, C.H.; ERBACH, D.C. Cornstalk residue shearing by rolling coulters. Transaction Of The ASAE, v. 29, n. 6, p.15301535, 1986.

EMBRAPA. Centro Nacional de Pesquisa de Milho e Sorgo (Sete Lagoas, MG). Cultura do milho, cultivares de milho 2005/2006. Consulta dos dados de cultivares de milho: Características agronômicas dos cultivares disponíveis no mercado, Sete Lagoas, 2004. On line. Disponível em: http://www.cnpms.embrapa.br/milho/cultivares/ consultas2.php3

JOBIM, C.C. et al. Silagem de grãos úmidos na alimentação de bovinos leiteiros. In: SIMPÓSIO GOIANO SOBRE MANEJO E NUTRIÇÃO DE BOVINOS DE CORTE E LEITE, 5., 2003, Campinas, SP. Anais... Campinas: CBNA (Org), 2003. V.1, p.357-376.

PRASAD, J.; GUPTA, C.P. Mechanical properties of maize stalk as related to harvesting. Journal Agriculture Engineering Research, v.20, p.79-87, 1975.

RIPPEL, C. et al. Evaluating particle size in Texas TMRs. Professional Animal Scientist, v.14, p.20-29, 1998.

RONSANI, A.J.; PARRÉ, J.L. Variação estacional da produção e do preço do leite no estado do Paraná - 1980 a 1999. Informe Gepec, Cascavel - Edunioeste, v.7, n.1, p.95-119, 2003.

SHINNERS K.J. et al. Design considerations and performance on a forage maceration device. American Society of Agricultural Engineers (ASAE). 0883-8542/88/04010013s02.00, v.4, n.1, 1988. 